\title{
Pomiar pamięci operacyjnej z zastosowaniem systemu komputerowego u pacjentów implantowanych - ocena trafności testu
}

\section{Working memory computerized measurement in patients with cochlear implant - evaluation of test validity}

\author{
Joanna Putkiewicz-Aleksandrowicz, Artur Lorens, Marika Kruszyńska, Anna Piotrowska, \\ Anita Obrycka, Tomasz Wiśniewski, Henryk Skarżyński
}

Instytut Fizjologii i Patologii Słuchu, Światowe Centrum Słuchu, Warszawa/Kajetany

Adres do korespondencji: Marika Kruszyńska, Światowe Centrum Słuchu, Zakład Implantów i Percepcji

Słuchowej, ul. Mokra 17, Kajetany, 05-830 Nadarzyn, e-mail: m.kruszynska@ifps.org.pl

\begin{abstract}
Streszczenie
Wprowadzenie: Rozumienie przekazów językowych jest najtrudniejszym i najbardziej złożonym zadaniem poznawczym związanym z interpretacją danych sensorycznych. Udział w nim biorą procesy myślenia, rozumowania i wnioskowania, które intensywnie wykorzystują pamięć operacyjną. Zniekształcony sygnał akustyczny docierający do użytkowników systemów implantów ślimakowych powoduje przeciążenie pamięci operacyjnej. W grupie pacjentów korzystających z systemu implantu ślimakowego obserwuje się znaczne różnice w dyskryminacji mowy, co może być spowodowane indywidualną sprawnością pamięci operacyjnej. Rozważania na temat związku pomiędzy pamięcią operacyjną a zdolnością dyskryminacji mowy posłużyły do przygotowania komputerowego testu pomiaru pamięci operacyjnej.
\end{abstract}

Cel: Celem pracy jest ocena trafności testu pomiaru pamięci operacyjnej u pacjentów implantowanych.

\begin{abstract}
Material i metody: Do tworzenia wersji komputerowej testu pamięci operacyjnej wykorzystano zadania, których konstrukcja została zainspirowana badaniami mierzącymi pojemność i sprawność przetwarzania informacji pamięci operacyjnej w komputerowej wersji testu pamięci operacyjnej. Badaniami sprawności pamięci operacyjnej przeprowadzonymi za pomocą opracowanego testu objęto grupę składającą się z 53 pacjentów, użytkowników systemów CI, oraz 20 ochotników prawidłowo słyszących. Trafność teoretyczną testu komputerowego oszacowano poprzez porównanie uzyskanych wyników pomiarów z oczekiwaniami teoretycznymi. Założono, że pacjenci z grupy najmłodszych i najstarszych użytkowników systemów implantów ślimakowych osiągną różne wyniki w teście oraz że wyniki osób z prawidłowym słuchem będą zbliżone do wyników osób korzystających z implantu w podobnej grupie wiekowej.
\end{abstract}

Wyniki: Użytkownicy systemu implantu w najstarszej grupie wiekowej mieli gorsze wyniki w stosunku do osób implantowanych w młodszych grupach wiekowych. Natomiast użytkownicy systemu implantu w młodszych grupach wiekowych osiągnęli podobne rezultaty jak osoby prawidłowo słyszące w podobnym wieku.

Wnioski: Uzyskane wyniki pozwoliły na stwierdzenie trafności wersji komputerowej testu pomiaru pamięci operacyjnej i umożliwiły wykorzystywanie go do badania użytkowników systemu implantu ślimakowego.

Słowa kluczowe: pamięć operacyjna • implant ślimakowy • badanie pamięci

Abstract

Background: Understanding language messages is one of the hardest and most complex cognitive tasks associated with the interpretation of sensory data. For the performance of this task, both the storage and processing functions of working memory are necessary. In cochlear implant patients, reduced clarity of the incoming auditory signal stresses the working memory system with negative consequences for discourse comprehension. Thus, inter-individual differences in working memory span can at least partially explain the broad distribution of listening comprehension ability after cochlear implantation. To facilitate the research on the link between working memory span and language comprehension after cochlear implantation a computerized test was prepared. 
Aims: To assess the construct validity of the computerized working memory span test designed for patients with a cochlear implant.

Material and method: A group-difference method was used to evaluate the construct validity of the computer version of the working memory operational span test. Theoretical assumptions led us to expect that the groups of younger and elderly CI users score differently in the test. We also expected that the test results of CI users should be similar to the results of age-matched individuals with normal hearing. These expectations were tested directly in $53 \mathrm{CI}$ patients and 20 subjects with normal hearing.

Results: Elderly CI patients got worse results in the working memory span test in comparison with the young ones. CI users achieved results comparable to those of age-matched individuals with normal hearing.

Conclusion: The results proved the construct validity of the proposed computerized version of the working memory span test designed for CI patients.

Key words: working memory $\bullet$ cochlear implant $\bullet$ memory

\section{Wprowadzenie}

Rozumienie przekazów językowych jest jednym z najtrudniejszych i najbardziej złożonych zadań poznawczych związanych $\mathrm{z}$ interpretacją danych sensorycznych. Biorą w nim udział procesy myślenia, rozumowania i wnioskowania, wymaga również uaktywnienia odpowiednich struktur wiedzy zapisanych głównie w pamięci semantycznej oraz intensywnie wykorzystuje pamięć operacyjną, często na granicy jej wydolności. Przez ostatnie ćwierć wieku psychologia poznawcza analizuje zjawisko przetwarzania językowego, korzystając z modelu pamięci operacyjnej. Pamięć operacyjna definiowana jest jako dynamiczny system podtrzymujący informacje podczas wykonywania operacji umysłowych. Jego elementy wzajemnie się wspierają i pracują częściowo niezależnie od siebie. Jest obszarem wzajemnego oddziaływania pamięci i różnych aspektów poznania, utrzymuje i kieruje informacjami w czasie, wykorzystując je do realizacji zadań poznawczych określanych np. jako umiejętność zrozumienia języka [1]. Pamięć operacyjna pełni funkcje nie tylko mnemiczne, lecz także kontrolne i regulacyjne - to złożony system procesów i mechanizmów kontrolujących i koordynujących przetwarzanie i magazynowanie informacji podczas aktywności poznawczej [2]. Jest to jednak system ograniczony pojemnościowo - oprócz ograniczenia ilościowego na pierwszy plan wysuwają się dwa ograniczenia czasowe: wynikające $\mathrm{z}$ tempa rozpadu śladu pamięciowego i $\mathrm{z}$ tempa przetwarzania informacji. Zasoby pamięci operacyjnej, które z natury są zawsze ograniczone, muszą zostać podzielone pomiędzy przetwarzanie i magazynowanie informacji [3].

System implantu ślimakowego, częściowo kompensując funkcję słyszenia, przekazuje do ośrodkowego układu nerwowego (OUN) zniekształconą, w różnym stopniu, informację o sygnale mowy [4]. Ponadto funkcje biologiczne przetwarzania informacji w OUN mogą być upośledzone przez deprywację sensoryczną spowodowaną niedosłuchem, doprowadzając do dalszej degradacji informacji o dźwiękach mowy [5]. Przetwarzanie zniekształconej lub/i niepełnej informacji o sygnale mowy prowadzi często do przeciążenia pamięci operacyjnej (wyczerpania jej zasobów) [6]. Istnieje hipoteza, że u użytkowników systemów implantów ślimakowych indywidualna sprawność pamięci operacyjnej może odgrywać kluczową rolę w rozumieniu przekazów językowych [7].

Wśród osób korzystających z implantu, zarówno dorosłych jak i dzieci, obserwuje się znaczne różnice w uzyskiwanych wynikach słuchowych [7,8]. Istnieją zarówno pacjenci, którzy osiągają wysokie wyniki w testach dyskryminacji mowy, jak i tacy, którzy mają zdecydowanie mniejsze korzyści. Wiedza i doświadczenia płynące z praktyki klinicznej i prac naukowo-badawczych pozwoliły wyłonić zmienne, takie jak wiek pacjenta, czas trwania głuchoty czy sposób komunikacji z otoczeniem, które różnicują wyniki uzyskiwane w tej grupie pacjentów [9]. Nadal otwarte pozostaje pytanie o przyczyny różnic w wynikach osób o takiej samej etiologii i czasie trwania głuchoty, w podobnym wieku, sposobie komunikacji z otoczeniem, u których zastosowano tego samego typu implant ślimakowy. Nie ma jednoznacznie zdefiniowanej grupy czynników, które w takim przypadku determinowałyby sukces implantacji u jednych osób lub niepowodzenie u innych. Poszukiwanie przyczyn tych różnic koncentruje się obecnie na funkcjonowaniu poznawczym jednostki, a zwłaszcza na indywidualnej sprawności pamięci operacyjnej. Nieliczne prace wskazują na związek między zdolnością dyskryminacji mowy, która konieczna jest do zrozumienia przekazów językowych, a funkcjami pamięci operacyjnej [7].

Powyższe rozważania stały się podstawą do rozpoczęcia badań nad związkiem pomiędzy funkcjonowaniem pamięci operacyjnej a rozumieniem przekazów językowych. Badania prowadzone są za zgodą komisji bioetycznej, w ramach projektu sfinansowanego ze środków Narodowego Centrum Nauki. Pierwszym zadaniem w tym projekcie było opracowanie i stworzenie stanowiska pomiarowego do oceny pamięci operacyjnej, które umożliwi sprawne wykonanie badań w licznej grupie użytkowników implantów ślimakowych. Opis tego stanowiska przedstawiono poniżej.

\section{Cel}

Celem pracy było przedstawienie pilotażowych wyników pomiarów zasobów pamięci operacyjnej oraz ocena trafności teoretycznej wersji komputerowej testu pamięci operacyjnej.

\section{Material i metody}

\section{Metoda}

\section{Opis stanowiska badawczego}

Do tworzenia komputerowej wersji testu pamięci operacyjnej wykorzystano zadania, których konstrukcja została zainspirowana badaniami mierzącymi pojemność i sprawność 
przetwarzania informacji pamięci operacyjnej [10]. Metoda podwójnego zadania (ang. dual task method) to metoda badania pamięci operacyjnej polegająca na wykonywaniu zadania poznawczego (na przykład rozumowania lub wykonywania operacji arytmetycznych) przy jednoczesnym obciążeniu pamięci innym zadaniem (na przykład przechowywaniem szeregu cyfr lub słowa). Paradygmat tych zadań angażuje zarówno magazynowe aspekty pamięci operacyjnej, jak i centralny system wykonawczy. Został on wybrany, ponieważ odpowiada sposobowi zaangażowania pamięci operacyjnej w trakcie procesu rozumienia przekazu ustnego, w przeciwieństwie do paradygmatu zadania prostego (ang. simple span task), który obejmuje jedynie procedury szacowania ilości informacji przechowywanych w pamięci roboczej. Procedury wykorzystywane w tym paradygmacie badawczym opierają się na ustalaniu maksymalnego obciążenia pamięci roboczej, niepowodującego jej przeładowania [11]. Na podstawie koncepcji tych zadań stworzono metodę dostosowaną do wymagań pacjenta korzystającego z systemu implantu ślimakowego. Skonstruowana przez zespół Instytutu Fizjologii i Patologii Słuchu komputerowa wersja testu prezentowana jest osobie badanej na ekranie monitora $\mathrm{w}$ formie wizualnej, aby uniknąć ryzyka błędu związanego $\mathrm{z}$ nierozumieniem treści prezentowanych $\mathrm{w}$ formie dźwiękowej. W ten sposób w teście mogą wziąć udział wszyscy użytkownicy systemu implantu ślimakowego, niezależnie od nabytych kompetencji słuchowych. Procedura badania obejmuje zadania wymagające dokonywania operacji na przechowywanym materiale i jednoczesnego zapamiętywania wskazanego elementu zadania. W badaniu wykorzystano zadania z zakresu operacyjnego (ang. operation-word span task), gdyż wykonywanie zadań z zakresu czytania (ang. reading span task) $\mathrm{w}$ przypadku osób $\mathrm{z}$ niedosłuchem mogłoby być zaburzone przez ograniczenia w kompetencjach językowych spowodowanych zwłaszcza niedosłuchem wrodzonym. Podczas testu badani rozwiązują zadania arytmetyczne i zapamiętują słowo towarzyszące temu zadaniu. Test składa się z pięciu serii, pomiędzy którymi nie ma przerw. W pierwszej serii osoba badana zapamiętuje dwa wyrazy, w drugiej trzy, w trzeciej cztery, w czwartej pięć i w piątej sześć. W załączniku 1. przedstawiono listy zadań opracowanych na potrzeby tworzonej wersji komputerowej testu.

Test rozpoczyna się pojawieniem się na ekranie pierwszej operacji matematycznej, która pozostaje na nim aż do udzielenia odpowiedzi. Osoba badana ocenia, czy operacja jest poprawna czy nie. Jeśli jest poprawna, badany mówi „tak”, a jeśli niepoprawna - „nie”. Po naciśnięciu odpowiedzi przez osobę badającą operacja znika z ekranu. Przez $800 \mathrm{~ms}$ ekran pozostaje pusty, następnie pojawia się wyraz, który znika również po $800 \mathrm{~ms}$, i ponownie pojawia się pusty ekran. Osoba badana wypowiada wyraz na głos i zapamiętuje go. Wtedy osoba badająca uruchamia kolejną operację. Pierwsza seria kończy się po dwóch zestawach. Na ekranie pojawia się znak „STOP”, a wtedy osoba badana ma powiedzieć na głos zapamiętane wyrazy. Sekwencja opisanych powyżej zadań została przedstawiona na rycinie 1 .

Czas trwania testu zależy od osoby badanej - od tego, ile czasu potrzebuje na rozwiązanie zadania matematycznego. Przeciętnie czas badania nie przekracza 30 minut. Wybrana przez nas wersja, w której do badania pamięci operacyjnej wykorzystywane są operacje liczbowe, jest jedną z najczęściej stosowanych i opisywanych w literaturze [12]. Osoba badana,

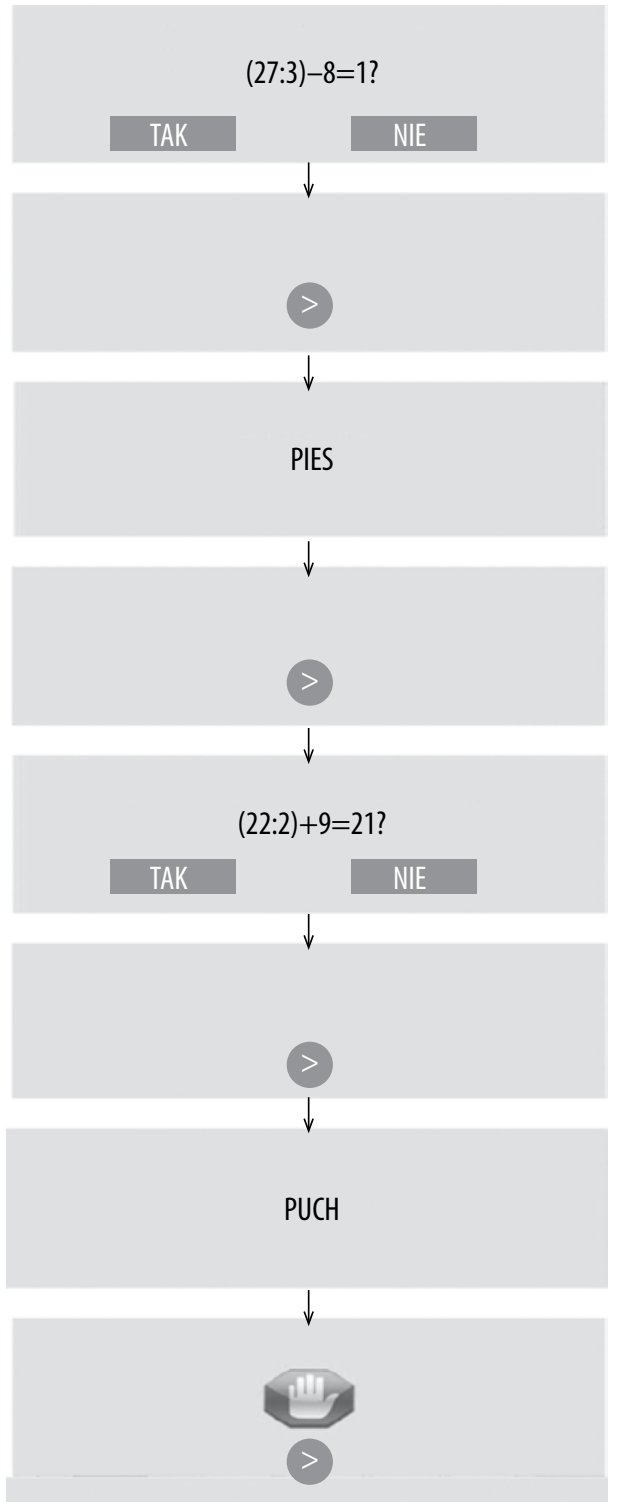

Rycina 1. Sekwencja zadań wykonywanych przez osobę badaną

Figure 1. Sequence of assignments done by a subject

zapamiętując i poprawnie powtarzając wszystkie słowa prezentowane w czasie badania, może uzyskać 60 punktów.

\section{Ocena trafności teoretycznej}

Trafność teoretyczną testu komputerowego oszacowano poprzez porównanie uzyskanych wyników pomiarów z oczekiwaniami teoretycznymi [13]. Posiłkując się teorią pamięci operacyjnej, sformułowano dwie hipotezy, których weryfikowanie na podstawie wyników wykonanych badań pozwoli ocenić trafność teoretyczną.

\section{Hipoteza 1}

Nie ma różnicy w zasobach pamięci operacyjnej pomiędzy osobami z niedosłuchem nabytym i osobami ze słuchem prawidłowym, które są w podobnym wieku [15]. 


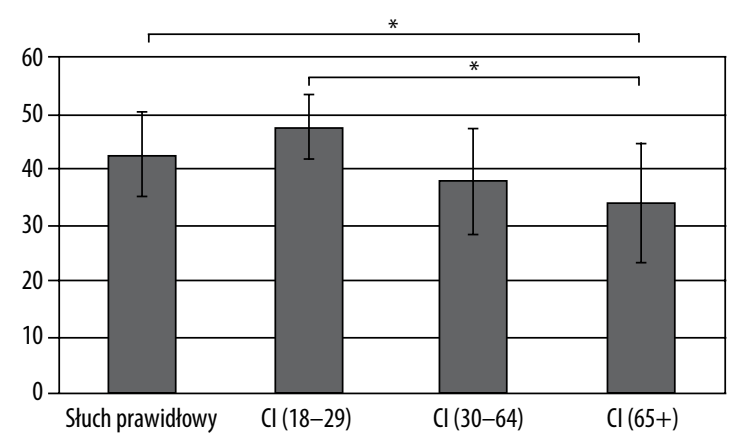

Rycina 2. Liczba prawidłowo zapamiętanych wyrazów w badanych grupach. Słupki oznaczają wartość średnią, a wąsy odchylenie standardowe

Figure 2. Number of correctly remembered words in test groups. Columns signify mean values, and parallel lines - standard deviations

\section{Hipoteza 2}

Zasoby pamięci operacyjnej wśród osób starszych są mniejsze niż u osób w młodym wieku [16].

Weryfikowania hipotez dokonano metodą ocen różnic międzygrupowych. W celu oceny istotności różnic pomiędzy średnimi w grupach wykonano analizę wariancji oraz testy post hoc Turkeya. Za istotne statystycznie przyjmowano wyniki dla poziomu istotności $\mathrm{p}<0,05$.

\section{Materiał}

Grupę badaną stanowiło 53 pacjentów z nabytym głębokim niedosłuchem odbiorczym, użytkowników systemów CI, oraz 20 ochotników prawidłowo słyszących. Do badań włączani byli kolejni dorośli pacjenci, bez dodatkowych niepełnosprawności, którzy zgłaszali się na planową wizytę dopasowania systemu implantu ślimakowego.

Pacjenci implantowani zostali podzieleni na trzy grupy, w zależności od wieku: od 18 do 29 lat, od 30 do 65 lat i powyżej 65 lat. Średnia wieku w grupie pierwszej $(n=6$, 3 kobiety, 3 mężczyzn) wyniosła 24 lata, w grupie drugiej ( $\mathrm{n}=32,24$ kobiety, 8 mężczyzn) wyniosła 47,3 lat, a w grupie trzeciej ( $n=15,10$ kobiet, 5 mężczyzn) 70 lat. Średnia wieku w grupie osób z prawidłowym słuchem $(n=20,13$ kobiet, 7 mężczyzn) wyniosła 30,6 lat.

\section{Wyniki}

Rycina 2 przedstawia wyniki uzyskane w grupach badanych.

Średnia liczba prawidłowo zapamiętanych wyrazów oraz odchylenie standardowe $\mathrm{w}$ grupie osób ze słuchem prawidłowym oraz $\mathrm{w}$ trzech grupach wiekowych użytkowników implantów ślimakowych wyniosły odpowiednio: $43,4(\mathrm{SD}=7,7) ; 48,8(\mathrm{SD}=5,9) ; 38,2(\mathrm{SD}=9,2)$ oraz 34,1 $(\mathrm{SD}=10,8)$.

Użytkownicy systemu implantu w grupie wiekowej 65+ osiągnęli statystycznie gorsze wyniki $(\mathrm{p}=0,029)$ w stosunku do użytkowników implantów w wieku poniżej 30 roku życia oraz do osób ze słuchem prawidłowym (średnia wieku: 30,6 lat). Nie stwierdzono różnic istotnych statystycznie w średnich liczbach prawidłowo zapamiętanych wyrazów miedzy grupą osób ze słuchem prawidłowym oraz grupami użytkowników implantów od 18 do 29 roku życia $(\mathrm{p}=0,72)$ oraz od 30 do 64 roku życia $(\mathrm{p}=0,26)$.

\section{Dyskusja}

Pamięć operacyjna jest systemem poznawczym przystosowanym do przechowywania oraz przetwarzania informacji w krótkim czasie, pełniąc rolę podobną do przetwarzania fonologicznego, i jest elementem centralnym w działaniach związanych z przetwarzaniem języka pisanego i mówionego [14]. Zagadnienie zasobów pamięci operacyjnej u osób $\mathrm{z}$ niedosłuchem jest $\mathrm{w}$ niewielkim stopniu opisane $\mathrm{w}$ literaturze naukowej [15]. Z nielicznych badań prowadzonych w tym zakresie wynika, że nie ma różnicy pomiędzy osobami z głuchotą postlingwalną a osobami ze słuchem prawidłowym [15]. Uzyskane w nich wyniki pozostawały takie same niezależnie od tego, czy badano ogólną pojemność pamięci operacyjnej czy specyficzne jej składniki. Dlatego w przeciwieństwie do systemu przetwarzania fonologicznego, pamięć operacyjna wydaje się być systemem poznawczym, który pozostaje względnie niezależny od utraty słuchu. Wyniki te są zbieżne $\mathrm{z}$ wynikami uzyskanymi w niniejszej pracy, w której użytkownicy systemu implantu osiągnęli podobne rezultaty jak osoby prawidłowo słyszące w porównywalnym wieku (potwierdzenie hipotezy 1). Natomiast użytkownicy systemu implantu w wieku $65+$ osiągnęli istotnie statystycznie gorsze wyniki w stosunku do osób implantowanych w młodszych grupach wiekowych (potwierdzenie hipotezy 2). Do zdolności umysłowych, które obniżają się wraz z wiekiem, należą między innymi różne aspekty pamięci, funkcje wykonawcze, szybkość przetwarzania umysłowego czy rozumowanie [16-18]. Biorąc pod uwagę rosnącą liczbę osób, które w momencie wszczepienia implantu mają powyżej 65 lat, istotna wydaje się analiza roli pamięci operacyjnej w procesie rozumienia mowy oraz związku wyników osiąganych w testach pamięci operacyjnej i wyników uzyskiwanych po zastosowaniu implantu ślimakowego, zwłaszcza w grupie osób w podeszłym wieku.

\section{Wnioski}

Uzyskane wyniki pilotażowych badań pojemności pamięci operacyjnej w trzech różniących się wiekiem grupach użytkowników implantu ślimakowego oraz w grupie osób ze słuchem prawidłowym potwierdzają trafność teoretyczną opracowanej wersji komputerowej testu pamięci operacyjnej. Test ten będzie wykorzystywany do badania zależności między możliwościami dyskryminacji mowy a pojemnością pamięci operacyjnej u pacjentów implantowanych. Autorzy mają nadzieję, że badania te przyczynią się do wyjaśnienia różnic w rozumieniu mowy, jakie występują wśród pacjentów z implantami ślimakowymi.

Projekt został sfinansowany ze środków Narodowego Centrum Nauki na podstawie decyzji nr DEC-2013/09/B/ST7/04213. 
Załącznik 1. Listy zadań wykorzystanych w wersji komputerowej testu pamięci operacyjnej

Annex 1. List of assignments used in a computerized test version

\section{PIERWSZA SERIA, \\ PO DWIE OPERACJE W ZESTAWIE}

$(27: 3)-8=1$ ? PIES

$(22: 2)+9=21 ?$ PUCH

STOP

$(16: 2)-5=3$ ? TARG

$(7 \times 2)+6=20$ ? SOK

STOP

$(3 \times 5)+6=21 ?$ KOT

$(24: 8)+4=8$ ? LAT

STOP

\section{DRUGA SERIA, \\ PO TRZY OPERACJE W ZESTAWIE}

$(2 \times 5)-6=3$ ? DUCH

$(9: 3)+7=10$ ? KOSZ

$(8: 2)-1=2$ ? LÓD

STOP

$(5 \times 5)+2=28$ ? PIACH

$(24: 8)+3=6 ?$ LOCH

$(4 \times 5)-11=8$ ? LIŚĆ

STOP

$(4 \times 4)-7=11$ ? KŁOS

$(3 \times 2)-4=2$ ? DOM

$(12: 2)=6+12$ ? LIST

STOP

\section{TRZECIA SERIA,}

\section{PO CZTERY OPERACJE W ZESTAWIE}

$(4 \times 5)-9=11$ ? LACD

$(7 \times 3)+4+25$ ? KIT

(3:3)-1+0? PŁAZ

$(24: 3)+3=11$ ? POT

STOP

(33:3) $-9=1$ ? KAT

$(25: 5)+7=13 ?$ GRUZ

$(6: 2)+9=12$ ? LAS

$(9 \times 2)-7=11$ ? LEK

STOP

$(8 \times 2)-8=9$ ? GAJ

$(18: 3)-2=5$ ? BAR

$(21: 7)-1=1$ ? LOCH

$(2 \times 3)+7=14$ ? SAD

STOP

\section{CZWARTA SERIA, PO PIĘĆ OPERACJI W ZESTAWIE}

$(5 \times 3)-6=9$ ? LÓD

$(6 \times 3)-9=9$ ? KĄT

$(6: 2)+7=11$ ? NIĆ

$(8 \times 3)-5=12$ ? DŻEM

$(9 \times 2)-7=11$ ? SKLEP

STOP

$(2 \times 7)-9=5$ ? DÓ

$(7 \times 3)-6=14$ ? LOCH

$(3 \times 4)+4=16$ ? GŁAZ

$(5 \times 5)-6=18 ?$ KOS

$(18: 3)+6=12$ ? DYM

STOP

$(5 \times 3)-8=7$ ? KARP

$(4: 2)+9=12$ ? LOK

$(6 \times 6)-6=31$ ? CYRK

$(2 \times 9)-9=10$ ? LACD

$(1 \times 2)+9=12$ ? BAK

STOP

\section{PIĄTA SERIA,}

PO SZEŚĆ OPERACJI W ZESTAWIE

$(5 \times 3)+4=18$ ? KURZ

$(6 \times 2)-3=8$ ? LIST

$(4 \times 4)-4=13$ ? KOT

$(3 \times 7)+6=27$ ? GROCH

$(9 \times 2)+6=24$ ? KLEJ

$(4 \times 3)-3=8$ ? BUT

STOP

$(6 \times 2)-5=7$ ? PUCH

$(9: 3)+2=5$ ? MYSZ

$(3 \times 4)-6=7$ ? KIJ

$(2 \times 5)+3=12$ ? $\mathrm{LOCH}$

$(8 \times 2)-7=8$ ? BUT

$(1 \times 8)+5=13$ ? KOS

STOP

$(4: 2)-9=11$ ? POT

$(5 \times 1)+6=12$ ? JEŻ

$(6: 2)-2=1 ?$ KOS

$(8: 2)+5=9$ ? PAL

$(3 \times 3)-5=7$ ? LAS

$(9 \times 1)-4=5$ ? MUŁ

\section{Piśmiennictwo:}

1. Nęcka E, Orzechowski J, Szymura B. Psychologia poznawcza. Warszawa; 2008, s. 349, s. 619.

2. Jagodzińska M. Psychologia pamięci. Gliwice; 2008, s. 182-3.

3. Baddeley AD, Hitch GJ. Working memory. W: Bower GH. red. The psychology of learning and motivation. New York, NY: Academic; 1974; 8: 47-89.

4. Skarżyński H, Lorens A, Piotrowska A. Wszczepy ślimakowe. W: Śliwińska-Kowalska M. Audiologia kliniczna. Łódź: Mediton, 2005; s. 429-42.

5. Shepherd RK, Hardie NA. Deafness-induced changes in the auditory pathway: implications for cochlear implants. Audiol Neurootol., 2001; 6(6): 305-18.
6. Hambrick DZ, Kane MJ, Engle RW. The Role of working memory in higher-level cognition. W: Sternberg RJ, Pretz JE. Cognition and intelligence: identifying the mechanisms of the mind. Cambridge: Cambridge University; 2005, s. 104-5.

7. Pisoni DB. Cognitive factors and cochlear implants: some thoughts on perception, learning, and memory in speech perception. Ear Hear, 2000; 1: 70-8.

8. Skarżyński H, Lorens A, Matusiak M, Porowski M, Skarżyński PH, James CJ. Cochlear implantation with the nucleus slim straight electrode in subjects with residual low-frequency hearing. Ear Hear; 2014; 35(2): 33-43. 
9. Lazard DS, Vincent C, Venail F, Van de Heyning P, Truy E, Skarżyński PH i wsp. Pre-, per- and postoperative factors affecting performance of postlinguistically deaf adults using cochlear implants: a new conceptual model over time. PLoS One, 2012; 7(11): e48739.

10. Friedman NP, Miyake A. The reading span test and its predictive power for reading comprehension ability. Journal of Memory and Language, 2004; 51: 136-8.

11. Daneman M, Carpenter PA. Indywidual differences in working memory and reading. Journal of Verbal Lerning and Verbal Behaviour, 1980; 450-66.

12. Klein K, Fiss WH. The reliability and stability of the Turner and Engle working memory task. Behav Res Methods Instrum Comput, 1999; 31(3): 429-32.

13. Fronczyk K. Psychometria, podstawowe zagadnienia. Warszawa: Wyższa Szkoła Finansów i Zarządzania w Warszawie; 2009.
14. Rönnberg J, Rudner M, Foo C, Lunner T. Cognition counts: A working memory system for ease of language understanding (ELU). Int J Audiol, 2008; 47(Suppl.2): 171-7.

15. Lyxell B, Andresson U, Borg E, Ohlsson I. Working-memory capacity and phonological processing in deafened adults and individuals with a severe hearing impairment. Int J Audiol, 2003; 87-8.

16. Costa PT, McCrae RR. Psychological research in the Baltimore Longitudinal Study of Aging. Gerontol, 1993; 26: 138-41.

17. Chatelin V, Kim EJ, Driscoll C, Larky J, Polite C. Cochlear implant outcomes in elderly. Otology \& Neurology, 2004; 298-301.

18. Deary IJ, Corley J, Gow A, Harris S, Houlihan LM, Marioni RE i wsp. Age-associated cognitive decline. British Medical Bulletin, 2009; 137-8. 